\title{
ICEBERGS: THEIR PHYSICAL DIMENSIONS AND THE PRESENTATION AND APPLICATION OF MEASURED DATA
}

\author{
by \\ I. Stuart Hotzel and John D. Miller \\ (Environmental Planning and Evaluation, Offshore Research, Petro-Canada Resources Inc., \\ Calgary, Alberta T2P 3E3, Canada)
}

\begin{abstract}
A knowledge of the dimensional characteristics of icebergs off the east coast of Canada is required for both scientific and engineering purposes. To fulfil this need, hydrocarbon exploration in the region has been supported by a program aimed at collecting morphometric data on icebergs. In addition to providing operational support for activities such as iceberg towing, this program has yielded information which will be useful for the engineering design of offshore structures. Functional relationships between the dimensions of icebergs are presented and ratios between the linear dimensions are examined. These ratios are used to calculate preliminary values for draft and mass on the Grand Banks and are demonstrated to give reasonable values for draft of icebergs off Greenland.
\end{abstract}

\section{INTRODUCTION}

Developments in oil exploration and production off the eastern coast of Canada are limited by the presence of icebergs and sea ice. I cebergs affect operations in two ways. First, because of the large mass of individual icebergs, drilling or production platforms must be designed to either withstand loads which an iceberg could impart to a structure or be capable of avoiding an iceberg. Second, subsea equipment on the ocean floor is at risk owing to collision with or scour from iceberg keels.

At the preliminary stages of platform selection and design, an understanding of the numbers of icebergs which pass a location, their temporal and spatial distribution, and their mass, draft, and general linear dimensions are essential. Petro-Canada Exploration Inc. has for the past several years been developing this understanding. This paper does not address all the concerns mentioned but rather it is the intent here to summarize data on the physical dimensions of icebergs in the Labrador Sea and, to a limited degree, on the Grand Banks of Newfoundland. Further, some discussion of relevant relationships between some of the more commonly measured dimensions are presented.

The relationship of height to draft has been widely used in the past (e.g. Robe 1976). This paper will show that other relationships demonstrate stronger correlations and that the applicability of any derived relationship is sensitive to the location where it is applied. The actual location for which such relationships are developed may itself influence the relationships, making them inappropriate for use in other iceberg-prone areas.

A discussion showing how these relationships may be used to calculate the draft and mass of icebergs in the Grand Banks region is presented.

\section{DATA PRESENTATION OF MEASURED ICEBERG PARAMETERS} OFF LABRADOR

The data

Most of the data was collected by the Labrador Group of Companies in support of exploratory drilling activity in the Labrador Sea during the period 1973 to 1978 . These data are restricted to the period from July through October, which is most favourable for drilling. The largest numbers of observations were made in August (49\%), followed by September $(26 \%)$, July $(19 \%)$, and October $(6 \%)$. The frequency of observations noted here is not comparable with the frequency of occurrence of icebergs as the data are biased by the scope and extent of the drilling program. The data were taken from well sites located between $52^{\circ} \mathrm{N}$ and $60^{\circ} \mathrm{N}$ lying on the offshore banks (Saglek, Nain, Makkovik, and Hamilton). A summary of the descriptive statistics is presented in Table I. Information on the areas of icebergs at the waterline, which was collected by the International Ice Patrol (IIP) in 1976, (US Coast Guard 1979) is used in conjunction with relationships between physical dimensions, which were derived from measurements on icebergs in the Labrador Sea, to calculate further physical dimensions. Types of icebergs

The complex shapes of icebergs defy simple classification. Several differing classifications were employed and these have been reduced to five common forms: pinnacle, drydock, domed, blocky, and tabular. The tabular iceberg is regarded as having undergone a minimum of degradation and erosion whereas the other forms bear witness to such activity in varying degrees.

The pinnacle iceberg was the most commonly observed form $(36 \%)$, followed by tabular $(29 \%)$, domed $(16 \%)$, drydock $(15 \%)$, and blocky $(4 \%)$ icebergs. If one simplifies this to a binary classification composed only of tabular and non-tabular forms, the data suggest that the latter occur more than twice 
TABLE I. STATISTICS OF ICEBERGS

\begin{tabular}{|c|c|c|c|c|c|c|c|c|}
\hline & Mean & Mode & Median & $\begin{array}{l}\text { Standard } \\
\text { deviation }\end{array}$ & Range & Maximum & Minimum & $\begin{array}{l}\text { Number of } \\
\text { observations }\end{array}$ \\
\hline Length $(\mathrm{m})$ & 120.0 & 65 & 94.0 & 90.0 & 545.0 & 550.0 & 5.0 & 232 \\
\hline Width (m) & 105.7 & 65 & 85.0 & 69.4 & 294.0 & 296.0 & 2.0 & 69 \\
\hline Height (m) & 30.7 & 15 & 23.3 & 22.3 & 101.5 & 103.0 & 1.5 & 234 \\
\hline Draft $(\mathrm{m})$ & 94.6 & 35 & 88.5 & 47.5 & 182.0 & 202.0 & 20.0 & 80 \\
\hline $\begin{array}{l}\text { Mass } \\
\left(x 10^{3} \text { tonne }\right.\end{array}$ & s) 184.2 & 50 & 387.5 & 4698.1 & 32839.0 & 32840.0 & 1.0 & 176 \\
\hline
\end{tabular}

as often as the less degraded forms ( $71 \%$ versus $29 \%$ ). Physical dimensions

The waterline Tength (defined as the longest horizontal dimension at the water plane) of icebergs in Labrador seas is shown to have a median value of $94 \mathrm{~m}$ with an extreme measured value of $550 \mathrm{~m}$. The histogram presented in Figure 1(b) illustrates the skewness of the data. Table I shows the statistics of the data.

The maximum height (defined as the distance between the waterline and the highest point of an iceberg) measured in Labrador seas was $103 \mathrm{~m}$ with a median value of $23.5 \mathrm{~m}$. The frequency distribution is presented in Figure $1(a)$. Further research may show that this dimension exhibits different relationships to other dimensions depending upon the degradation of the iceberg. For example, the ratio of height to mass is quite different for partially degraded (tabular) icebergs than for extremely degraded (pinnacle) icebergs al though the actual measured height on these two types may be similar.

Draft is a particularly important dimension. For example, to those interested in iceberg scour, a knowledge of draft provides a means of determining the probable numbers of recent scour marks and the areas where scour is most likely to occur. Also, accurate knowledge of draft enables calculation of the depths needed to bury equipment in order to protect it from interaction with iceberg keels. Data from Labrador (Fig.1(c)) show a median value of $89 \mathrm{~m}$ for draft and a maximum value of $202 \mathrm{~m}$. This upper value is similar to an upper value of $187 \mathrm{~m}$ measured off west Greenland (Danish Hydraulic Institute 1979).

The estimated mass of an iceberg is an estimate based upon one of several models which employ information on dimensions and shapes. Results, to date, from the Labrador Sea indicate that most masses $(78 \%)$ in this area are less than $2 \times 10^{6}$ tonnes. Maximum estimated masses are approximately $30 \times 10^{6}$ tonnes with median and modal values of $390 \times 10^{3}$ and $50 \times 10^{3}$ tonnes respectively. Figure $1(\mathrm{~d})$ and Table I show the data and data statistics.

RELATIONSHIPS BETWEEN MEASURED DIMENSIONS OF ICEBERGS Relationship of length to other dimensions

Table II shows relationship of length to height as approximately $3: 1$; however, this ratio is highly variable, ranging from $0.5: 1$ to $50: 1$. Figure $2(\mathrm{c}$ ) illustrates this variability.

The ratio of width to length shows width to be some $80 \%$ of the length. This relationship demonstrates that use of the waterline length as an effective diameter of the iceberg is not unduly conservative.

The ratio of mass to length is approximately $4 \times 10^{3}$ to $5 \times 10^{3}$ tonnes of mass per metre of length, if averaged over all iceberg sightings. Examination of the raw data shows that a simple ratio such as this cannot be used as a predictive tool because the ratio of mass to length is proportional to actual iceberg size; that is, the ratio between mass to length increases as the mass of the iceberg increases. The range in ratios is illustrated in Table II and Figure 2(a) and is between $130 \times 10^{3}$ tonnes of mass per metre of length at approximately $30 \times 10^{6}$ tonnes and $1 \times 10^{3}$ tonnes of mass per metre of length at approximately $30 \times 10^{3}$ tonnes.

TABLE II. STATISTICS FOR ICEBERG RATIO DATA

\begin{tabular}{|c|c|c|c|c|c|c|c|c|c|}
\hline Ratio & Mean & Mode & Median & $\begin{array}{r}\text { Standard } \\
\text { deviation }\end{array}$ & Range & Maximum & Minimum & $\begin{array}{c}\text { Number of } \\
\text { Observations }\end{array}$ & $\begin{array}{c}\text { Mean square } \\
\text { value }\end{array}$ \\
\hline Width/Length & 0.74 & 0.85 & 0.77 & 0.21 & 1.17 & 1.45 & 0.29 & 67 & 0.60 \\
\hline Draft/Length & 0.67 & 0.70 & 0.63 & 0.32 & 1.49 & 1.69 & 0.19 & 74 & 0.55 \\
\hline Height/Length & 0.28 & 0.30 & 0.32 & 0.18 & 2.26 & 2.29 & 0.02 & 230 & 0.11 \\
\hline Mass/Length & 10.81 & 5.00 & 4.29 & 17.15 & 130.43 & 130.43 & 0.01 & 168 & 410.92 \\
\hline Draft/width & 0.93 & 0.70 & 0.81 & 0.42 & 2.20 & 2.59 & 0.39 & 48 & 1.04 \\
\hline Height/Width & 0.36 & 0.35 & 0.32 & 0.16 & 0.96 & 1.08 & 0.12 & 68 & 0.15 \\
\hline Mass/Width & 17.61 & 5.00 & 8.20 & 27.00 & 166.57 & 166.67 & 0.10 & 66 & 1039.15 \\
\hline Height/Draft & 0.41 & 0.35 & 0.35 & 0.18 & 0.93 & 0.97 & 0.04 & 75 & 0.20 \\
\hline Mass/Draft & 25.10 & 5.00 & 11.40 & 34.32 & 166.13 & 166.67 & 0.54 & 55 & 1807.95 \\
\hline
\end{tabular}


(a)

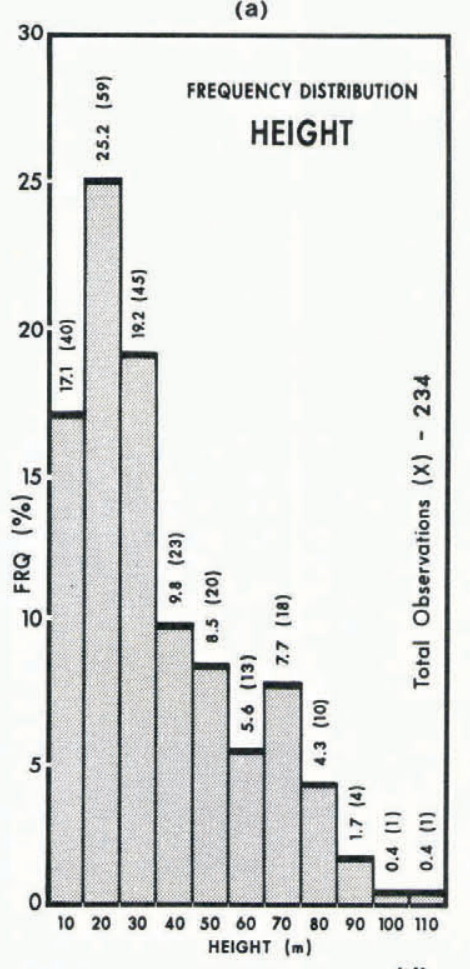

(d)

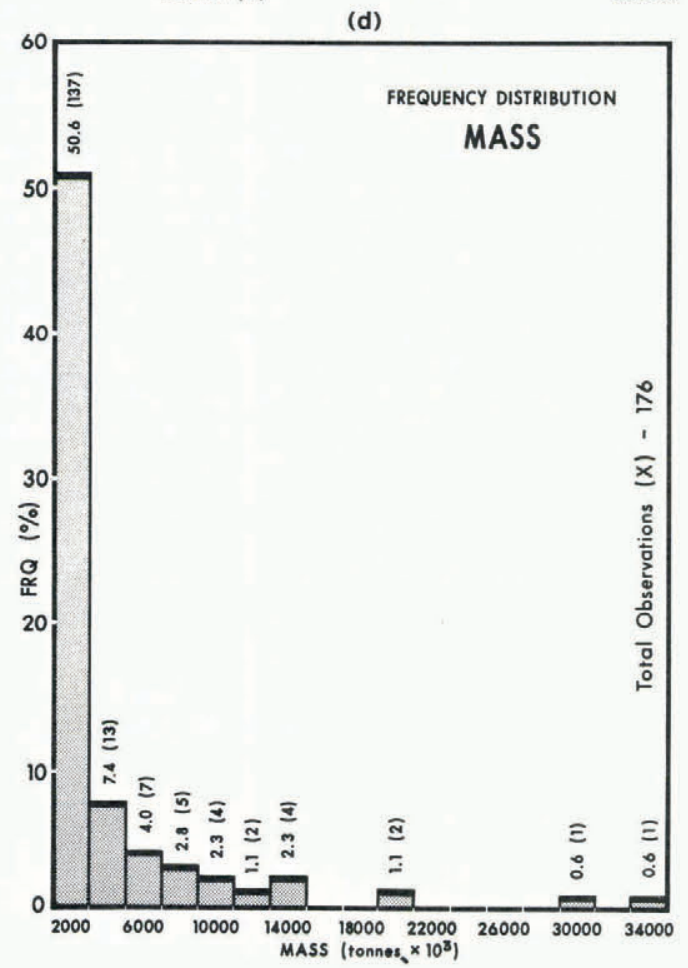

(b)
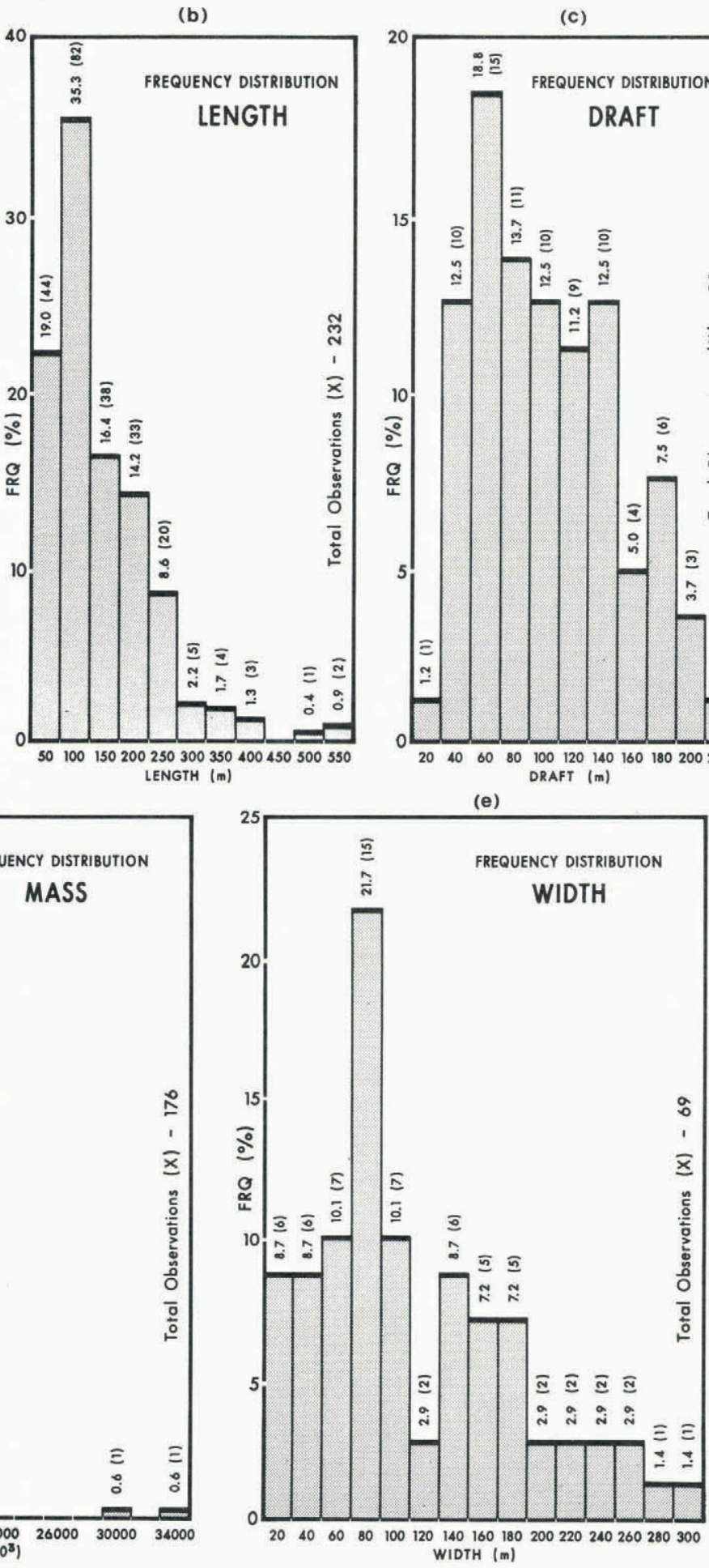

Fig.1. Frequency distributions of selected physical dimensions of icebergs: (a) height, (b) length, (c) draft, (d) mass, and (e) width. 

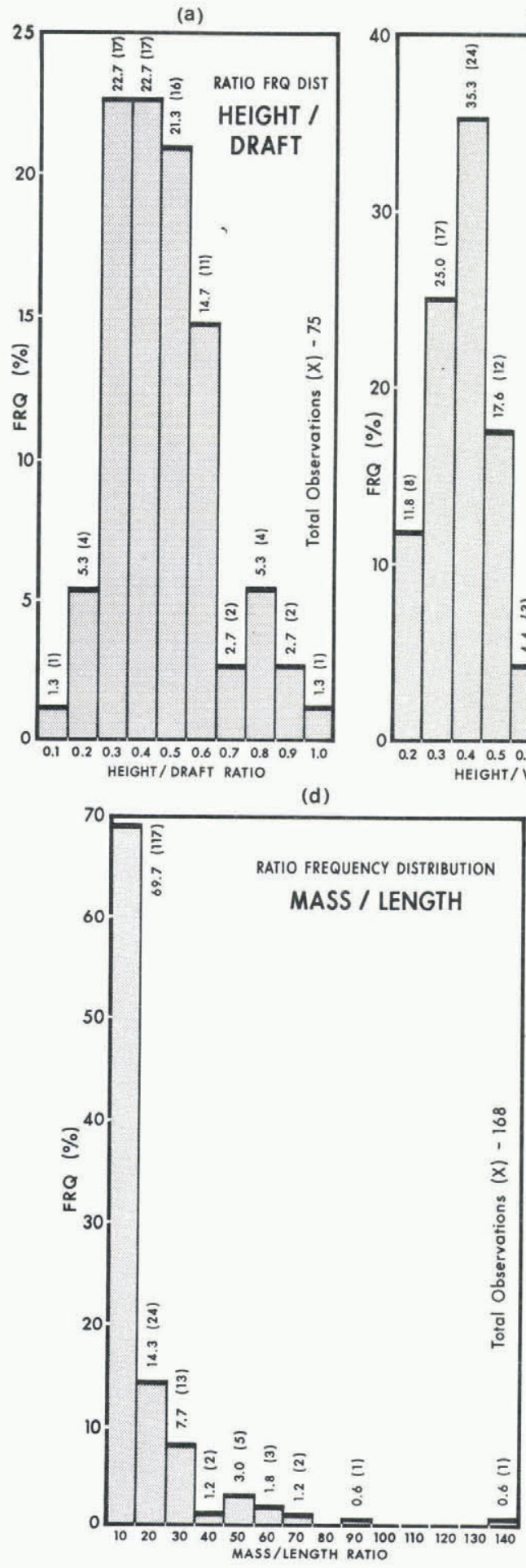

(b)
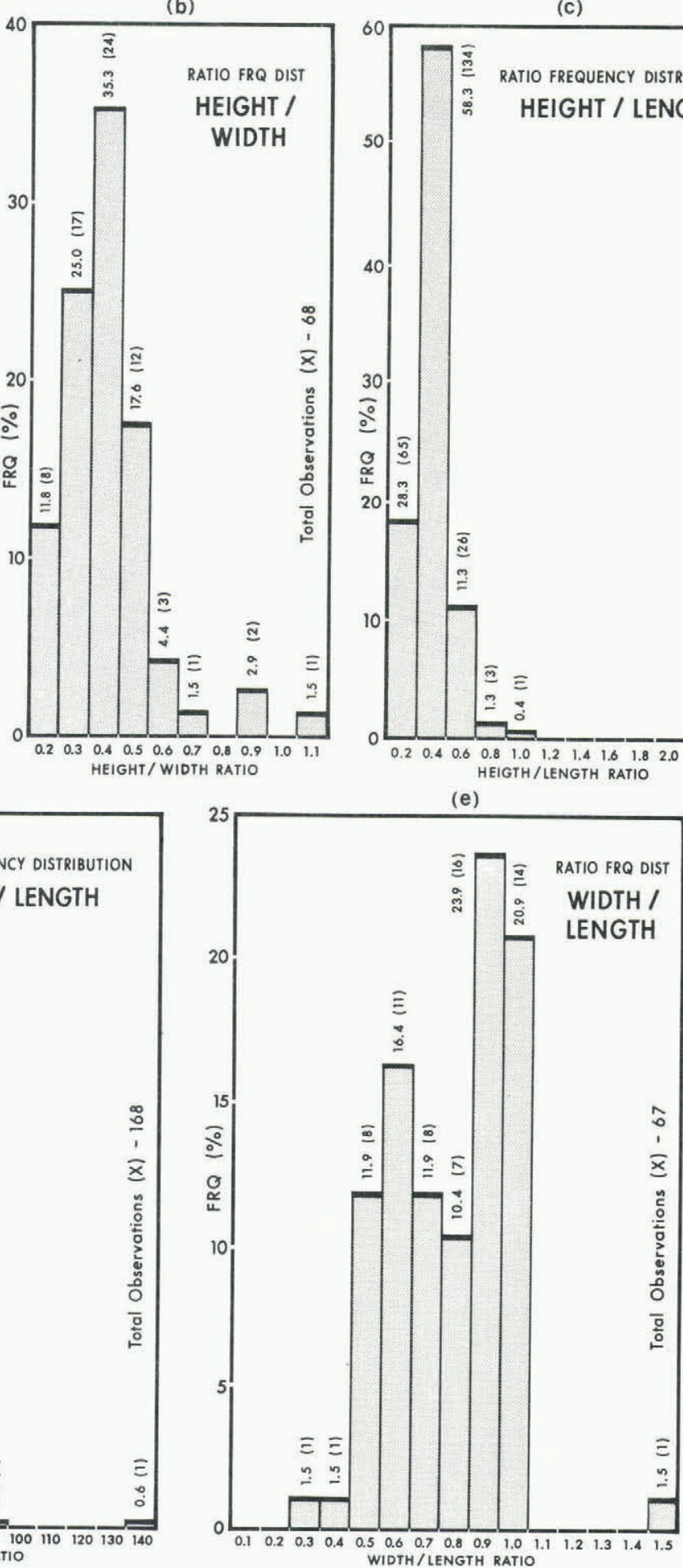

(c)

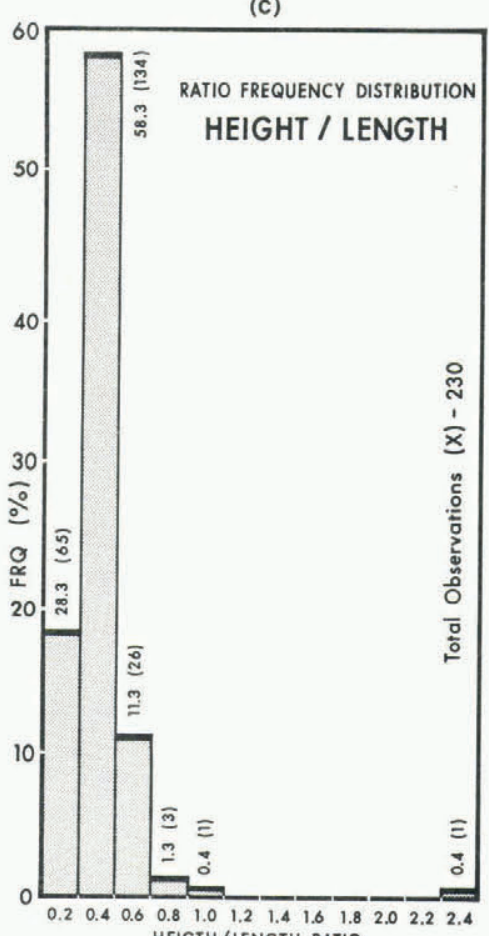
HEIGTH/LENGTH RATIO

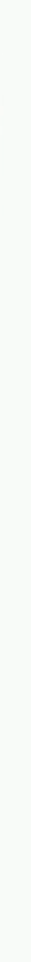

Fig.2. Frequency distributions of selected ratios between physical dimensions of icebergs: (a) height : draft, (b) height: width, (c) height : length, (d) mass : length, and (e) width : length. 

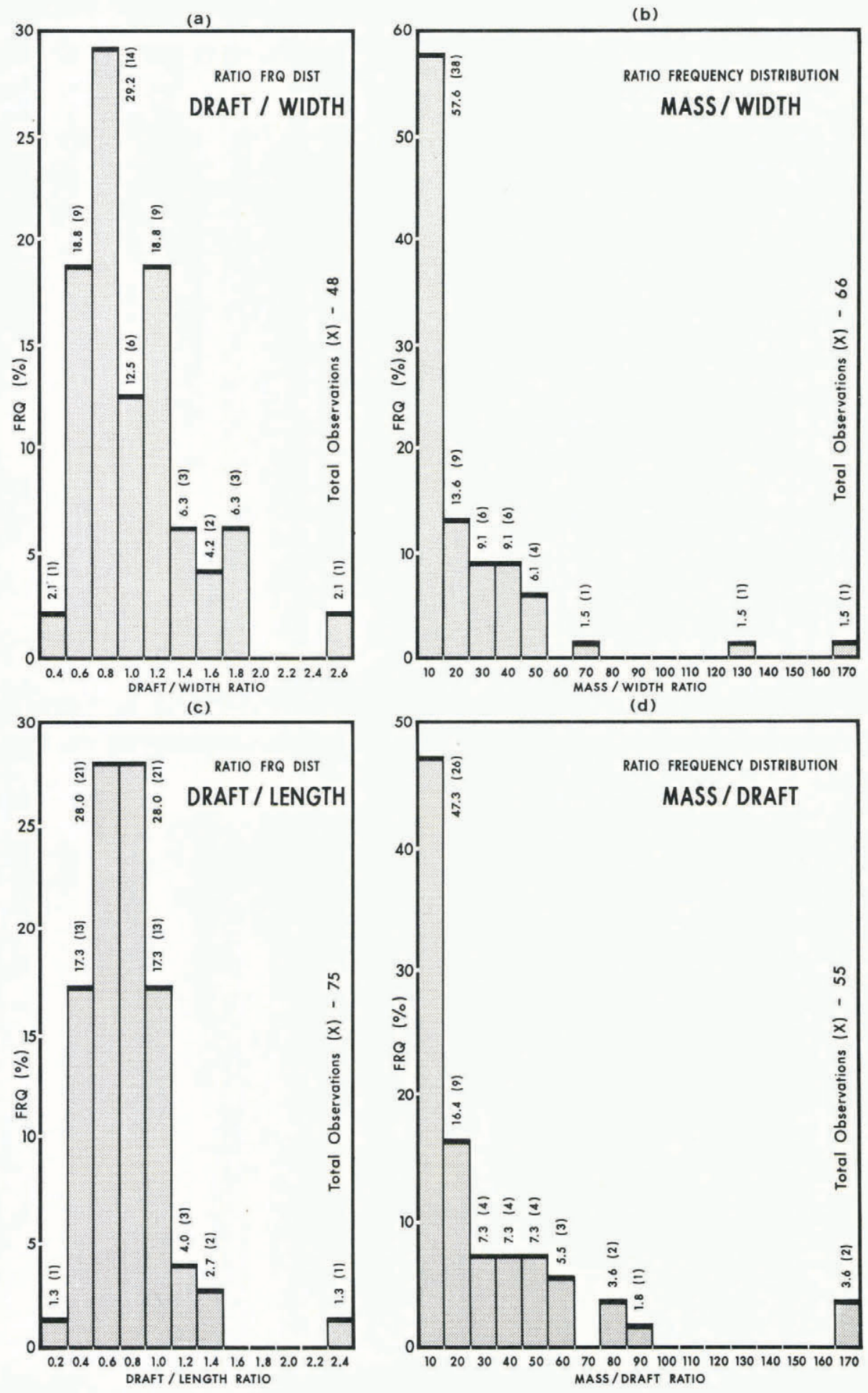

Fig.3. Frequency distributions of selected ratios between physical dimensions of icebergs: (a) draft : width, (b) mass : width, (c) draft : length, and (d) mass : draft. 
The central tendency measures of the ratio of draft to length vary from 0.6 to 0.7 using the data from Labrador. Lewis and Benedict (1981) estimate that icebergs may increase their draft after rolling by as much as $20 \%$. Figure $3(c)$ and Table II show that less than $10 \%$ of the drafts exceed waterline length with two extreme cases where draft exceeded the waterline length by 50 to $60 \%$. The mass of these icebergs ranged from $400 \times 10^{3}$ to $600 \times 10^{3}$ tonnes. Relationships of dimensions of an iceberg to its draft

Ratios of height to draft are a popular method for estimating the drafts of icebergs (e.g. Robe 1976) despite obvious flaws. An iceberg which is only slightly degraded may have the same height as a degraded iceberg. Assuming that they both have similar linear dimensions, the degraded iceberg must have a smaller total mass and would thus presumably float higher in the water and consequently have a smaller drafi (assuming similar underwater shapes) than the more massive, slightly degraded iceberg. If this tenet holds true one might expect that the ratio of height to draft probably varies not only with mass but also with shape, making this particular relationship a poor predictive tool. This paper is not intended to criticize the past use of this relationship (at a time when less data were available for icebergs), but rather to suggest that other relationships are simpler to use and provide better estimates.
Table II and Figure 2(a) show that the bulk of the data indicates a ratio between 0.2 and 0.6 .

The ratios of mass to draft have the same inherent problem as the ratios of mass to length in that both sets of ratios are a function of iceberg mass. The ratio of mass to draft varies between $166 \times 10^{3}$ tonnes of mass per metre of draft at $30 \times 10^{6}$ tonnes to 940 tonnes of mass per metre of draft at $30 \times 10^{3}$ tonnes of mass.

\section{FUNCTIONAL RELATIONSHIPS}

The measurement of the dimensions of icebergs, is dangerous, time-consuming and expensive. In many cases it is possible to obtain one or more above-water dimensions from visual or photographic information. When this information is coupled with a suitable functional relationship it may be possible to infer, to a first approximation, the dimensions of other variables such as draft.

To define potential relationships a simple regression of the logarithinically transformed values was undertaken. These relationships were defined for each of the classifications of iceberg type (tabular, domed, pinnacle, blocky, drydock) as well as for all types combined. The functional relationships are presented in the power function format $\left(Y=a x^{b}\right)$ in Table III, which also includes the correlation coefficient and the number of observations. As an example,

TABLE III. FUNCTIONAL RELATIONSHIPS BETWEEN PARAMETERS OF ICEBERG DIMENSIONS

\begin{tabular}{|c|c|c|c|c|c|c|}
\hline Type & Y & $x$ & $\mathrm{~N}$ & $\mathrm{R}$ & A & B \\
\hline All icebergs & $\begin{array}{l}\text { Draft } \\
\text { Width } \\
\text { Height } \\
\text { Mass } \\
\text { Mass } \\
\text { Draft }\end{array}$ & $\begin{array}{l}\text { Length } \\
\text { Length } \\
\text { Length } \\
\text { Length } \\
\text { Draft } \\
\text { Mass } \\
\end{array}$ & $\begin{array}{r}75 \\
67 \\
230 \\
168 \\
55 \\
55 \\
-\end{array}$ & $\begin{array}{l}0.74 \\
0.94 \\
0.83 \\
0.90 \\
0.78 \\
0.78 \\
\end{array}$ & $\begin{array}{l}3.781 \\
0.7118 \\
0.4025 \\
0.002009 \\
0.01470 \\
17.245\end{array}$ & $\begin{array}{l}0.63 \\
1.00 \\
0.89 \\
2.68 \\
2.50 \\
0.232 \\
\end{array}$ \\
\hline Tabular & $\begin{array}{l}\text { Draft } \\
\text { Width } \\
\text { Height } \\
\text { Mass } \\
\text { Mass }\end{array}$ & $\begin{array}{l}\text { Length } \\
\text { Length } \\
\text { Length } \\
\text { Length } \\
\text { Draft }\end{array}$ & $\begin{array}{l}19 \\
11 \\
41 \\
34 \\
15 \\
---\end{array}$ & $\begin{array}{l}0.64 \\
0.94 \\
0.77 \\
0.93 \\
0.82 \\
-\end{array}$ & $\begin{array}{l}1.552 \\
0.3104 \\
0.1142 \\
0.0001 \\
0.05961 \\
\end{array}$ & $\begin{array}{l}0.79 \\
1.19 \\
1.12 \\
3.38 \\
2.16\end{array}$ \\
\hline Domed & $\begin{array}{l}\text { Draft } \\
\text { Width } \\
\text { Height } \\
\text { Mass } \\
\text { Mass }\end{array}$ & $\begin{array}{l}\text { Length } \\
\text { Length } \\
\text { Length } \\
\text { Length } \\
\text { Draft }\end{array}$ & $\begin{array}{r}6 \\
5 \\
22 \\
18 \\
3 \\
---\end{array}$ & $\begin{array}{l}0.76 \\
0.15 \\
0.73 \\
0.79 \\
0.68 \\
-\end{array}$ & $\begin{array}{l}5.958 \\
41.26 \\
0.2752 \\
0.001125 \\
0.2491\end{array}$ & $\begin{array}{l}0.48 \\
0.16 \\
0.92 \\
2.68 \\
1.70\end{array}$ \\
\hline Pinnacle & $\begin{array}{l}\text { Draft } \\
\text { Width } \\
\text { Height } \\
\text { Mass } \\
\text { Mass }\end{array}$ & $\begin{array}{l}\text { Length } \\
\text { Length } \\
\text { Length } \\
\text { Length } \\
\text { Draft }\end{array}$ & $\begin{array}{l}23 \\
20 \\
56 \\
37 \\
18 \\
-\end{array}$ & $\begin{array}{l}0.55 \\
0.93 \\
0.86 \\
0.91 \\
0.65 \\
-\end{array}$ & $\begin{array}{l}10.91 \\
0.16 \\
0.657 \\
0.01026 \\
0.05961\end{array}$ & $\begin{array}{l}0.43 \\
0.85 \\
0.83 \\
2.31 \\
2.23 \\
-\end{array}$ \\
\hline Blocky & $\begin{array}{l}\text { Draft } \\
\text { Width } \\
\text { Height } \\
\text { Mass } \\
\text { Mass }\end{array}$ & $\begin{array}{l}\text { Length } \\
\text { Length } \\
\text { Length } \\
\text { Length } \\
\text { Draft }\end{array}$ & $\begin{array}{l}5 \\
1 \\
6 \\
1 \\
1\end{array}$ & $\begin{array}{l}0.83 \\
0.72\end{array}$ & $\begin{array}{r}16.44 \\
1.00\end{array}$ & $\begin{array}{l}0.39 \\
0.66\end{array}$ \\
\hline Drydock & $\begin{array}{l}\text { Draft } \\
\text { Width } \\
\text { Height } \\
\text { Mass } \\
\text { Mass }\end{array}$ & $\begin{array}{l}\text { Length } \\
\text { Length } \\
\text { Length } \\
\text { Length } \\
\text { Draft }\end{array}$ & $\begin{array}{r}10 \\
11 \\
25 \\
14 \\
7\end{array}$ & $\begin{array}{l}0.68 \\
0.91 \\
0.85 \\
0.85 \\
0.54\end{array}$ & $\begin{array}{l}2.638 \\
0.5067 \\
0.3946 \\
0.01046 \\
4.527\end{array}$ & $\begin{array}{l}0.71 \\
1.04 \\
0.90 \\
2.23 \\
1.04\end{array}$ \\
\hline
\end{tabular}

$\mathrm{Y}, \mathrm{X}=$ I ceberg parameters

$A, B=$ Regression equation parameters

$\mathrm{N}=$ Number of data pairs

$\mathrm{R}=$ Correlation coefficient 
the relationship between length $\mathrm{L}$ and height $\mathrm{H}$ for all iceberg types has the form

$$
H=0.402 L^{0.89} \text {. }
$$

The correlation coefficient is 0.83 , and 230 pairs of observations were used to define the relation.

In employing these relationships one should note their strength and the size of the data set, and review the applicability of such a mathematical form which uniquely defines a dependant $y$-value from a specified input and is defined from a model with minimal variance.

\section{USE OF FUNCTIONAL RELATIONSHIPS TO ESTIMATE OTHER} DIMENSIONS OF ICEBERGS

Length is the simplest and probably the most accurate dimension which can be measured for an iceberg. It would be beneficial, therefore, if other dimensions which are difficult, costly or dangerous to attain, such as draft, could be estimated from data which can be collected more easily. To this end, an evaluation of the accuracy or applicability of some of the identified dimensional relationships is made. As draft and mass are the two most critical parameters with regard to offshore oil exploration or engineering design, emphasis will be given to their calculation in the ensuing discussion.

In an earlier paper (Hotzel and Miller in press) it was demonstrated that the power curve equation for mass to draft derived for tabular and pinnacled icebergs in Labrador seas worked reasonably well when applied to data collected off the coast of west Greenland (Danish Hydraulic Institute 1979). From zero to $110 \mathrm{~m}$, calculated drafts compare extremely well, with $86 \%$ of the calculated data lying within $\pm 25 \%$ of the line, indicating a perfect correlation between observed and predicted values (see Fig.4). Given that the technique used to measure iceberg drafts is imprecise, the accuracy of the estimates is believed to be close to, or within, the accuracy of the technique.

At the larger sizes (> $3 \times 10^{6}$ tonnes) the power curve equation appears to underestimate draft. Two possible explanations for this are that there are insufficient numbers of observations at these larger masses so that the power curve equation is imprecise and that a better relationship could be attained if the present data were partitioned.

It is believed that some of the relationships such as power curves for length to draft ratios calculated from data from the Labrador Sea may represent a distinct statistical ensemble and may not apply in other areas where icebergs occur. Investigation of the dependence of the statistical relationships concerning iceberg characteristics at different sites is currently underway.

\section{ESTIMATION OF MASS AND DRAFT OF ICEBERGS ON THE GRAND BANKS}

In 1976, the IIP measured the waterline areas of some 104 icebergs on the Grand Banks of Newfoundland from aerial photography (US Coast Guard 1979). As one of the few publicly available and rigorous data sets of measurements of icebergs made on the Grand Banks, these data provided an opportunity to use some of the power curve relationships developed from the data from the Labrador Sea.

As the IIP data were presented as waterline areas it was necessary to estimate a more commonly measured

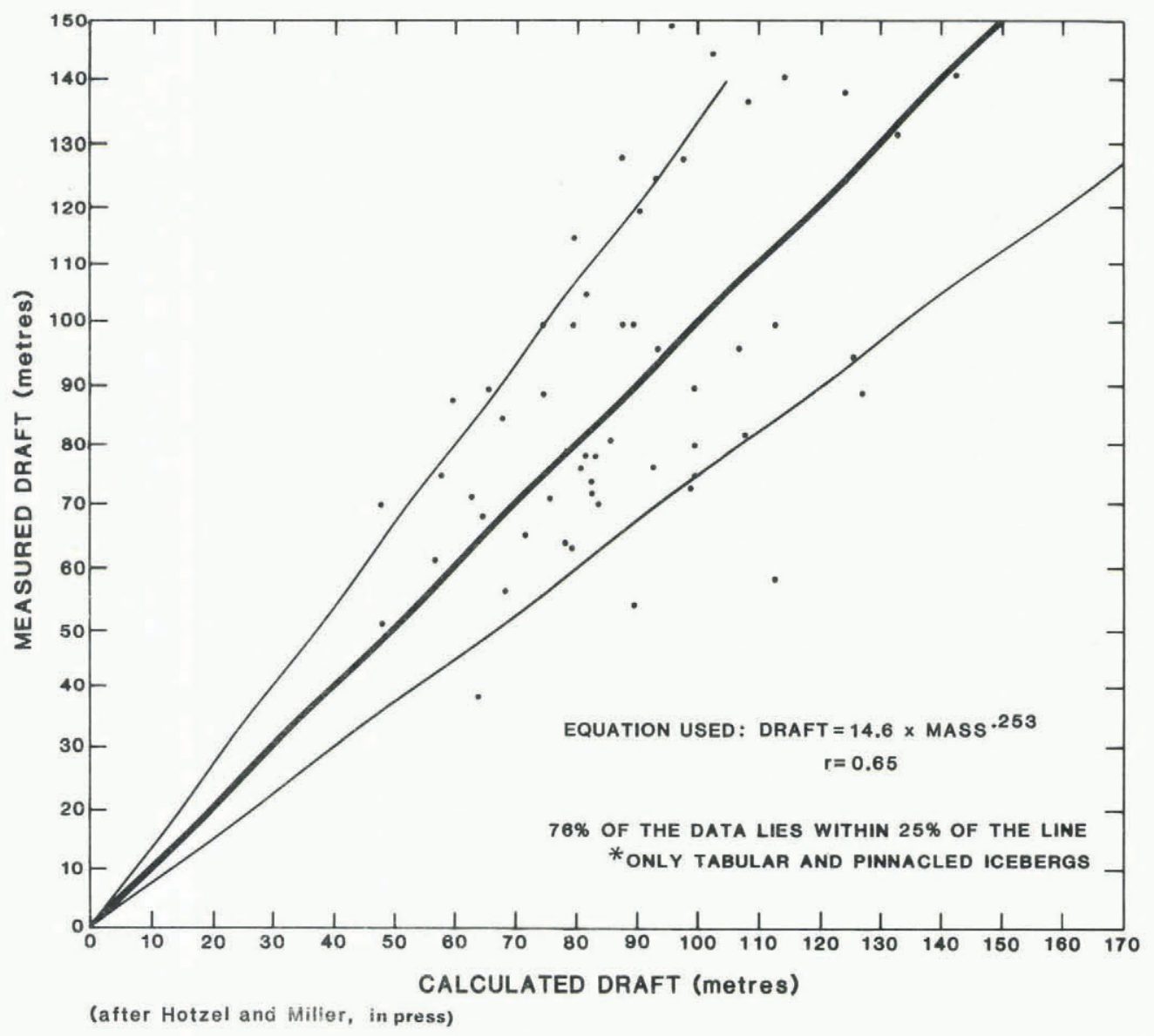

Fig.4. Measured draft vs calculated draft for 49 icebergs* off Greenland using a power curve equation. 
linear dimension from these areas, and waterline length was chosen. Certain basic assumptions about iceberg shape were made: that the planimetric section of the iceberg was circular in form and the length was taken as twice the characteristic circle radius.

Values of length calculated in the initial phase of this study were used to calculate draft, using the power curve formula

$$
3.781 \times \text { length } 0.63 \text {. }
$$

The cumulative frequency distribution of these data is presented in Figure 5 . It is interesting to

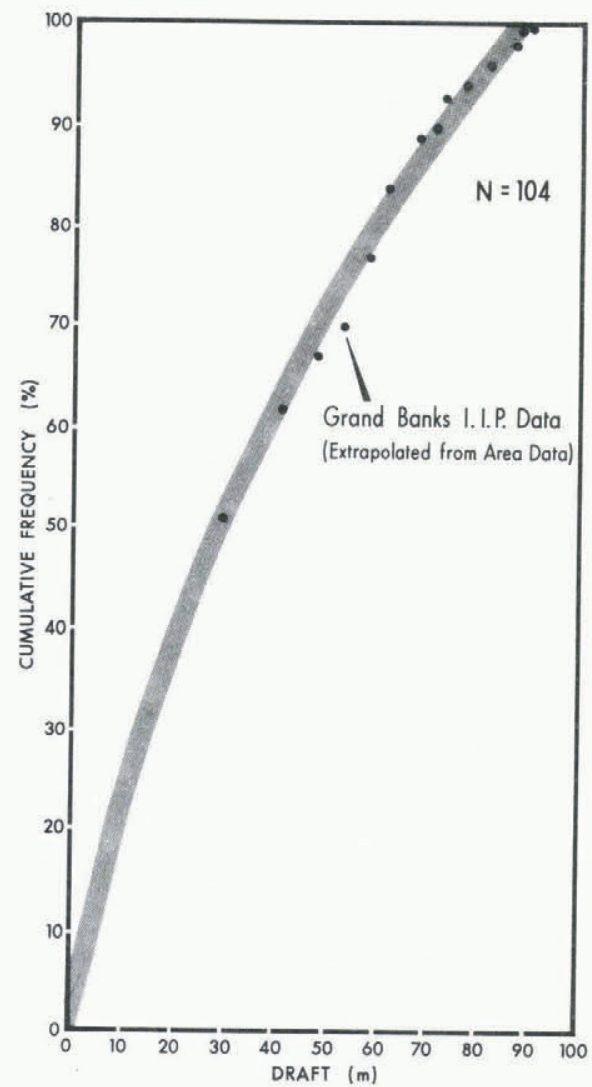

Fig.5. Cumulative frequency distribution for drafts calculated from IIP data.

note that the calculated drafts truncate at approximately $90 \mathrm{~m}$ which is also the maximum water depth over much of the Grand Banks. This suggests that the relationship fits reasonably well with respect to the physical environment, as revealed by the bathymetry of the region.

A cumulative frequency distribution of mass was also produced and from this a table showing percentage exceedence values* is presented (Table IV).

The cumulative frequency distributions indicate that on the Grand Banks, during the period of measurement, the median mass and draft are $11 \times 10^{3}$ tonnes and $29 \mathrm{~m}$ respectively, with extreme icebergs at the $5 \%$ exceedance level some $800 \times 10^{3}$ tonnes mass and $79 \mathrm{~m}$ draft.

* The percentage exceedence value may be defined as the percentage amount equal to or greater than the calculated value; it is equivalent to one minus the value given by the cumulative frequency distribution at the calculated value.
TABLE IV. PERCENTAGE EXCEEDENCES OF ICEBERGS ON THE GRAND BANKS (from IIP (1976))

$\begin{array}{ccc}\begin{array}{c}\text { Percent } \\ \text { exceedence }\end{array} & \begin{array}{c}\text { Mass } \\ \left(\times 10^{3} \text { tonnes }\right)\end{array} & \begin{array}{c}\text { Draft } \\ (\mathrm{m})\end{array} \\ 50 & 11 & 29 \\ 25 & 202 & 57 \\ 15 & 322 & 64 \\ 10 & 509 & 71 \\ 5 & 799 & 80 \\ 2 & 1240 & 87\end{array}$

\section{CONCLUDING REMARKS}

This paper summarizes a series of measurements of the physical dimensions of icebergs collected by the Labrador Group of Companies in support of offshore exploration for $0 i 1$ and gas. In addition, functional relationships amongst iceberg dimensions and ratios between the major linear dimensions are presented. The use of these relationships in estimating other dimensions and the applicability of these relations in other regions is discussed. The derived functional relationships have been used, together with data on waterline areas, to calculate preliminary estimates of mass and draft of icebergs for the Grand Banks. Work is now underway to upgrade and refine the relationships and their regional and physical dependencies.

\section{REFERENCES}

Danish Hydraulic Institute 1979 Environmental conditions offshore west Greenland. Vol 4. Icebergs. Horsholm, Danish Hydraulic Institute

Hotzel I S, Miller J D In press. Relationships between measured iceberg dimensions. In Proceedings of the ice score workshop, Montebello, Québec

Lewis J, Benedict C P 1981 Icebergs on the Grand Banks: oil and gas considerations. World oil 192(1): 109-114

Robe R Q 1976 Height to draft ratios of icebergs. In POAC 75: the third Intermational Conference on Port and Ocean Engineering under Aretic Conditions, Fairbanks, Alaska, 1975. Proceedings Vol 1: 407-415

US Coast Guard 1979 Report of the International Ice Patrol Service in the North Atlantic Ocean. Season of 1976. US Coast Guard Bulletin 62 